\title{
Flow Diversion for Intracranial Aneurysm Management: A New Standard of Care
}

\author{
Fawaz Al-Mufti ${ }^{1}$ Krishna Amuluru ${ }^{1}$ C Chirag D. Gandhi ${ }^{1,2,3}$. \\ Charles J. Prestigiacomo ${ }^{1,2,3}$
}

Published online: 9 May 2016

(C) The American Society for Experimental NeuroTherapeutics, Inc. 2016

\begin{abstract}
Endovascular treatment of intracranial aneurysms with complex morphologies such as giant, wide-necked, or fusiform aneurysms is challenging. Stent-assisted coiling and balloon-assisted coiling are alternative techniques to treat such complex aneurysms, but studies have shown less-thanexpected efficacy, as suggested by their high rate of recanalization. The management of complex aneurysms via microsurgery or conventional neuroendovascular strategies has traditionally been poor. However, over the last few years, flowdiverting stents (FDS) have revolutionized the treatment of such aneurysms. FDS are implanted within the parent artery rather than the aneurysm sac. By modifying intra-aneurysmal and parent-vessel flow dynamics at the aneurysm/parent vessel interface, FDS trigger a cascade of gradual intraaneurysmal thrombosis. As endothelialization of the FDS is complete, the parent vessel reconstructs while preserving the patency of normal perforators and side branch vessels. As with any intervention, the practice and application of flowdiversion technology is inherent, with risks that include vessel rupture or perforation, in-stent thrombosis, perforator occlusion, procedural and delayed hemorrhages, and perianeurysmal edema. Herein, we review the devices, their mechanisms of actions, clinical applications, complications, and ongoing studies.
\end{abstract}

Fawaz Al-Mufti

fa299@njms.rutgers.edu

1 Department of Neurosurgery, Rutgers University School of Medicine, Newark, NJ, USA

2 Department of Neurology, Rutgers University School of Medicine, Newark, NJ, USA

3 Department of Radiology, Rutgers University School of Medicine, Newark, NJ, USA
Keywords Flow diversion · Cerebral aneurysm ·

Subarachnoid hemorrhage $\cdot$ Endovascular $\cdot$ Coil embolization

\section{Introduction}

The worldwide prevalence of intracranial aneurysms is estimated to be between $5 \%$ and $10 \%$, and the incidence of reported ruptured aneurysms is about 10 in every 100,000 persons per year (about 30,000 individuals per year in the USA). Ruptured aneurysms occur most commonly in people aged between 30 and 60 years. Not all cerebral aneurysms rupture, and some small aneurysms may be monitored for growth or onset of symptoms. Furthermore, aggressive management of coexisting medical problems and risk factors such as hypertension may preclude the need for intervention in certain situations. Each case is unique, and considerations for treating an unruptured aneurysm include features of the aneurysm such as type, size, and location, risk of rupture, the individual's age and general health, personal and family medical history, and the risks of intervention. Traditionally, 2 interventional options have been available for treating cerebral aneurysms: microvascular clipping and endovascular coil embolization, both of which carry some risk to the individual, such as vessel damage, aneurysm recurrence and rebleeding, and postoperative stroke.

Despite advances in early detection and interventions of aneurysmal subarachnoid hemorrhage (SAH) in the neurocritical care setting, SAH continues to be associated with high morbidity and mortality. These high mortality rates are further emphasized by the fact that $10 \%$ of these patients die prior to reaching the hospital, $25 \%$ die within $24 \mathrm{~h}$ of $\mathrm{SAH}$ onset, and $45 \%$ die within 30 days [1]. 
For decades, microsurgical clipping of an intracranial aneurysm was considered the standard of care in patients who undergo definitive therapy. The International Subarachnoid Aneurysm trial (ISAT) was a sentinel study that challenged the therapeutic monopoly of microsurgical clipping and changed the landscape of traditional management of intracranial aneurysms [2, 3]. Since then, endovascular embolization of intracranial aneurysms has been integral in the management of both ruptured and unruptured aneurysms.

Still, many aneurysms such as giant, wide-necked (aneurysms with a dome-to neck ratio of $<2$ ), and fusiform are considered more challenging and less amenable to traditional endovascular coil embolization [4]. Stentassisted coil embolization and balloon-assisted coil embolization were alternative techniques developed to deal with such complex aneurysms, but studies have shown less-than-expected efficacy given high rates of recanalization $[4,5]$.

Recently, flow-diverting stents (FDS) have become viable options for many of these complex aneurysms, which were previously considered unamenable to prior treatment techniques $[6,7]$. Here, we review the current state of FDS, their mechanisms of action, clinical applications, updates, efficacy, and complications for the treatment of intracranial cerebral aneurysms [8].

\section{Mechanism of Action and Flow Dynamics}

The mechanism of action of FDS is based on 2 concepts: the disruption of blood flow from the parent artery into the aneurysm, and provision of a scaffold on which endothelial cells can grow and therefore isolating the aneurysm from the parent artery [8]. Flow diversion reduces the blood flow across the aneurysm neck by altering flow dynamics both across and within the cerebral aneurysm, leading to thrombosis. Additionally, FDS promote endoluminal neointimal growth, causing parent vessel reconstruction while eliminating the aneurysmparent vessel interface [9, 10]. Following deployment of the FDS, the aneurysm begins to thrombose, and subsequently shrinks and collapses around the deviceconstruct [11]. Over the ensuing 6-12 months, as endothelialization progresses and aneurysmal thrombosis continues, the parent vessel is reconstructed with eventual aneurysmal occlusion (Fig. 1) [7, 12, 13]

The metallic surface area coverage of FDS is approximately $30-50 \%$ of the total surface area of the aneurysm neck and the porosity is $60-76 \%$ compared with $89 \%$ porosity in stents used in stent-assisted coiling. This optimal balance between porosity and pore density allows for the preservation of perforators and small branches, while achieving aneurysmal thrombosis,
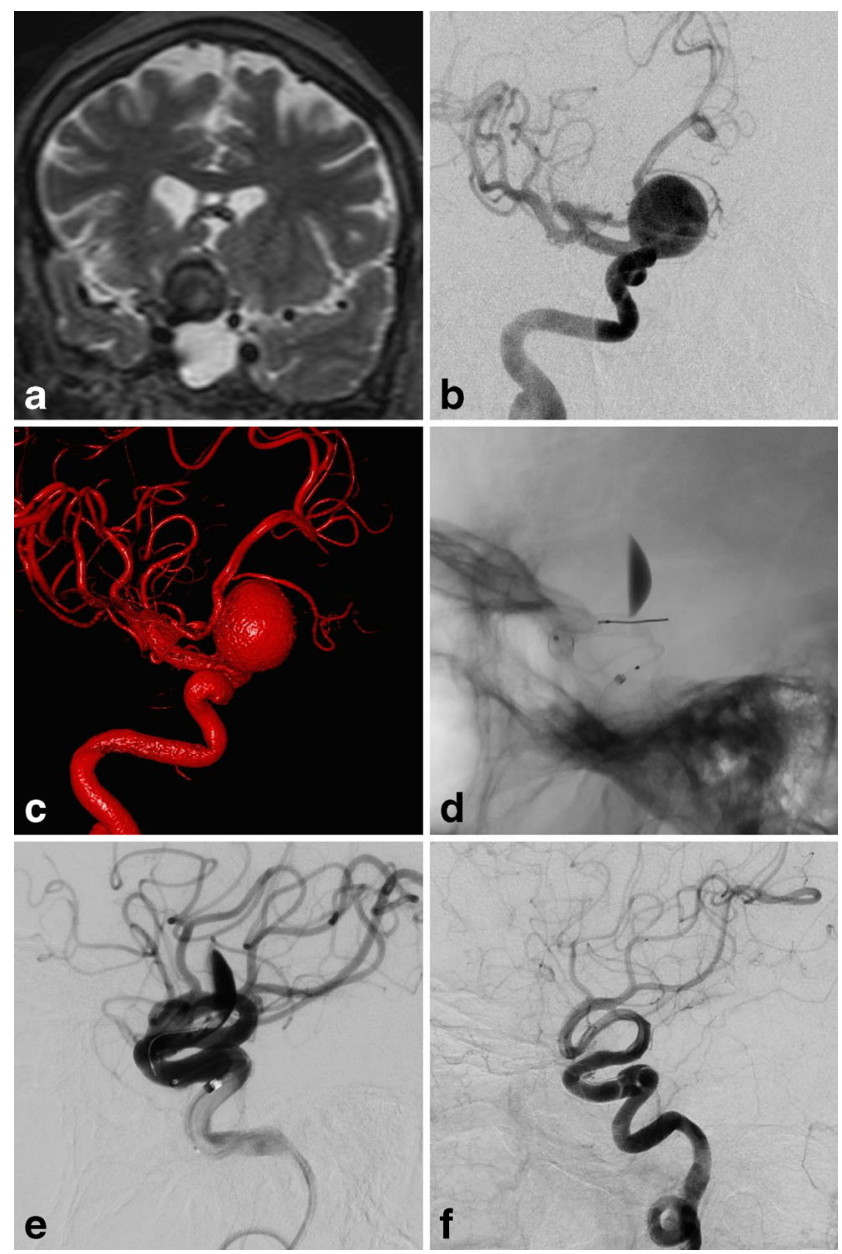

Fig. 1 a Coronal T2-weighted magnetic resonance image of the brain shows large paraclinoid right internal carotid artery (ICA) aneurysm with mass effect on the optic chiasm. b Digital subtraction angiogram (DSA) and $\mathbf{c} 3$-dimensional volume-rendered reconstruction shows wide-necked aneurysm. d Unsubtracted lateral view and e DSA of right ICA in lateral view immediately after flow diverter stent placement shows layering contrast stagnation in aneurysm and patent anterograde flow. f Sixmonth follow-up DSA shows vessel reconstruction with no further filling of aneurysm

reduction in rupture risk and recanalization rates of treated aneurysms.

FDS are designed to provide sufficient coverage across the aneurysm neck to exclude the lesion from circulation but to be porous enough to preserve the patency of any branch vessels covered by the construct through the interstices of the device [14-16]. One of the hallmarks of flow diversion is the reduction of inflow into an aneurysm, while maintaining flow to normal vasculature [17-19]. Additionally, they can be safely deployed across the ostium of a branching artery (i.e., anterior choroidal or ophthalmic arteries), and the flow-demand for normal tissue perfusion will generate a pressure gradient sufficient to maintain anterograde flow through the stent wall [20]. 


\section{Devices and Intraprocedural Techniques}

\section{Pipeline Embolization Device}

The pipeline embolization device (PED; ev3/Covidien, Irvine, CA, USA) is Conformité Européenne (CE) marked and is the only flow-diversion stent that has been approved by the Food and Drug Administration (FDA) for use in the USA. The PED is made of $25 \%$ platinum and $75 \%$ nickel-cobalt-chromium alloy and has a porosity of $65-70 \%$.

The single-arm Pipeline for Uncoilable or Failed Aneurysms study (PUFS) established the safety and efficacy profile of the first-generation PED [11]. This study enrolled patients with aneurysms of the internal carotid artery (ICA) from petrous through superior hypophyseal segments that were $>10 \mathrm{~mm}$ in diameter with a neck that was $>4 \mathrm{~mm}$ in diameter. The aneurysms were either unamenable to, or had failed, endovascular coiling. The trial showed that the aneurysm occlusion rate was $73.6 \%$ at 6 months, and the major complication rate, including ipsilateral stroke or neurologic death, was $5.6 \%$ (Table 1). Technical device deployment success rate was $99 \%$ [11].

Another multicenter, prospective, single-arm study, The Pipeline Embolization Device for the Intracranial Treatment of Aneurysms trial (PITA) studied the application of PED in wide-necked aneurysms $>4 \mathrm{~mm}$, with a dome/neck ratio $<1.5$, or had failed previous therapy [12]. In this trial, the aneurysm occlusion rate was $93.3 \%$, and there were no deaths. Ischemic stroke occurred in $6.5 \%$. Other large, clinical, multicenter trials, such as the International Retrospective Study of the PED, a multicenter aneurysm treatment study (IntrePED), showed comparably high rates of complete occlusion of aneurysms of the ICA and a reasonably low rate of major safety events [28].

A recent systematic review on the clinical outcomes of PED used in the treatment of 905 patients with 1043 aneurysms showed that the cumulative mortality rate was $2.3 \%$ [29]. The risk of ischemic strokes and transient ischemic attacks were $1.9 \%$ and $2.0 \%$, respectively, and $2.3 \%$ of patients had intracranial hemorrhage. The 6-month aneurysm occlusion rate was $79.7 \%$. The authors concluded that the complication and mortality rates associated with PED may be similar to other contemporary endovascular techniques, with a better 6-month aneurysm occlusion rate [29].

The second-generation PED, named Pipeline Flex (ev3/ Covidien), received the CE Mark of approval in March 2014 and subsequently received FDA approval in February 2015. A prospective, single-center study of 44 cases reported a $98 \%$ success rate, with no procedural complications. There was a $4.5 \%$ incidence of postoperative complications [30]. Unfortunately, to date, long-term follow-up data on aneurysm occlusion rates using PED are currently lacking.

Currently, the PED is the only FDS that is FDA-approved for use in the USA for treatment of aneurysms originating from the petrous through superior hypophyseal segments of the ICA that measure $>10 \mathrm{~mm}$ in diameter with a neck measuring $>4 \mathrm{~mm}$ in diameter. There are no FDS that are cleared for use in the posterior circulation. Additional FDS are CE marked, as described below.

\section{SILK FDS}

The SILK FDS (SFD; Balt Extrusion, Montmorency, France) is a closed-cell mesh cylinder comprised of 48 braided nitinol strands and $35-\mu \mathrm{m}$ platinum microfilaments resulting in a high coverage of approximately $35 \%$ [31]. It has a porosity of $45-60 \%$. An advantage of the SFD delivery system is that it can be resheathed and repositioned at up to $90 \%$ deployment [21].

The SFD was CE Mark-approved in 2008 for intracranial circulation use in Europe but is currently available for clinical use in the USA. A multicenter registry of consecutive patients treated with SFD enrolled 92 patients with 103 aneurysms [22]. The overall deployment success rate was $96 \%$ with a postprocedural SAH and device-related deaths of $3.8 \%$ and $2.2 \%$, respectively. The median follow-up for the entire cohort was 1 year (range $0.25-2$ years), with an overall mortality rate of $4.3 \%$ and permanent morbidity of $8.7 \%$ (Table 1 ). Residual filling of the aneurysm was seen in 13 patients $(16.9 \%)[22]$.

Table 1 Results of recent trials for flow diversion

\begin{tabular}{lllllll}
\hline Device & $\begin{array}{l}\text { Patients } \\
\text { (aneurysms) } \\
(n)\end{array}$ & $\begin{array}{l}\text { Successful } \\
\text { deployment } \\
(\%)\end{array}$ & ICH (\%) & $\begin{array}{l}\text { Mortality } \\
(\%)\end{array}$ & $\begin{array}{l}\text { Periprocedural } \\
\text { complications } \\
(\%)\end{array}$ & $\begin{array}{l}\text { Delayed aneurysm } \\
\text { occlusion }\end{array}$ \\
\hline PED [11] & $905(1043)$ & 99 & 2.3 & 2.3 & 5.6 & $80 \%$ at 6 months \\
SILK [21, 22] & $92(103)$ & 96 & 4.3 & 4.3 & 10.9 & 79.2 at 12 months \\
Surpass [23, 24] & $165(190)$ & 98 & 6.2 & 2.7 & 11.4 & $75 \%$ at 6 months \\
FRED [25] & $29(34)$ & 100 & 0 & 0 & 13.8 & $73 \%$ at 6 months \\
p64 [26, 27] & $121(130)$ & 97 & 0 & 0.8 & 2.3 & $87.7 \%$ at 9 months \\
\hline
\end{tabular}

$\mathrm{ICH}=$ intracranial hemorrhage; $\mathrm{PED}=$ pipeline embolization device; $\mathrm{FRED}=$ flow redirection endoluminal device system 
Other studies on the second-generation SILK + stent described improved safety and efficacy profiles both during the periprocedural phase or at follow-up [32].

In a meta-analysis of prospective and retrospective studies using SFD, ischemic complications and parent artery occlusion each occurred in $10 \%$, and the aneurysm rupture rate was $3.5 \%$, while the cumulative mortality was $4.9 \%$. The 12 month aneurysm occlusion rate was $81.8 \%$ [33].

Although high-quality studies are limited, a meta-analysis comparing SFD with PED showed comparable rates of procedure-related and device-related complications, as well as comparable clinical outcomes, including mortality. However, a comparison of aneurysm occlusion rate of PED versus SFD was not elucidated [34].

\section{Surpass FDS}

The Surpass FDS (Stryker Neurovascular, Fremont, CA, USA) is a cobalt-chromium, low porosity, self-expanding, tubular-shaped, braided mesh stent [20]. It was CE Markapproved in Europe in 2011 and is available in the USA under an investigational device exemption.

Surpass has a low porosity of $70 \%$ and a uniformly distributed high pore density of $21-32$ pore $/ \mathrm{mm}^{2}$ that remains constant, regardless of the stent diameter [23]. Unlike other FDS, the manufacturer does not recommend telescoping multiple devices or deploying multiple stents within the same vessel segment. This allows preservation of perforator and side branch vessel patency [23].

Although prospective randomized studies are lacking, the safety and efficacy of Surpass were examined in a prospective, multicenter, nonrandomized, single-arm study of clinical and angiographic results for the treatment of intracranial aneurysms [24]. The study included aneurysms with wide necks $(>4 \mathrm{~mm})$, and/or dome-toneck ratios of $\leq 2$, and were considered difficult to treat with current surgical or endovascular techniques. Successful flow diversion was achieved in $98 \%$ of cases. At 6 months, neurologic death and any stroke occurred in $12 \%$, of which $6.2 \%$ were due to hemorrhage. Permanent neurologic morbidity and mortality were seen in $6.0 \%$ and $2.7 \%$, respectively. Follow-up angiography was available in $86.8 \%$ of the subjects, revealing complete occlusion in $75 \%$ (Table 1) [24].

The Surpass IntraCranial Aneurysm Embolization System Pivotal Trial (SCENT; Stryker) to treat large or giant wideneck aneurysms is an ongoing, prospective, multicenter, single-arm trial designed to examine efficacy and safety of the Surpass FDS for FDA approval. Patients being enrolled have aneurysms $\geq 10 \mathrm{~mm}$ with $\mathrm{a} \geq 4 \mathrm{~mm}$ neck located on the ICA to the level of the terminus [35].

\section{Flow Redirection Endoluminal Device System}

The flow redirection endoluminal device system (FRED; MicroVention, Tustin, CA, USA) is a next-generation, closed-cell, paired-stent flow diversion device and is currently CE-Marked in Europe. FRED has a unique integrated dual-layer (stent-within-a-stent) design with an outer, high-radial force stent and an inner, low-porosity, flow-diverting mesh composed of 48 braided nitinol strands. FRED can be resheathed after up to $50 \%$ deployment. This compliant closed-cell device is designed to allow simultaneous deployment and retrieval by a single operator.

A small, single-center observational clinical study examined the safety and efficacy of FRED in the endovascular treatment of aneurysms with a fundus-toneck ratio $<2$ or neck diameter $>4 \mathrm{~mm}$, fusiform, dissecting, or giant aneurysms [25]. Deployment was technically successful in all cases. The primary end point of safety was reached in $26 / 29$ patients $(90 \%)$; in the 3 remaining patients, 1 developed a disabling ischemic stroke and 2 developed minor strokes with complete recovery at follow-up. At 3-month follow-up, complete occlusion was achieved in $56 \%$ of patients, and by 6 months $73 \%$ had complete aneurysmal occlusion (Table 1) [25]. The Pivotal Study is an open label, prospective trial that is currently enrolling patients to establish the safety and efficacy of the FRED stent system in the management of intracranial aneurysms [36].

\section{p64 Flow Modulation Device}

The p64 flow modulation device (Phenox, Bochum, Germany) is one of the newer FDS and received the CE Mark of approval in 2012. The p64 device is a fully resheathable, detachable FDS in the form of a braided mesh tube, composed of a 64 nickel-titanium alloy (nitinol) with radiopaque markers along the length of the device. It is available in sizes of $2.5-5 \mathrm{~mm}$ diameter and $12-36 \mathrm{~mm}$ length. Owing to a controlled mechanical detachment, a unique feature of the p64 device is that it can be retrieved into the microcatheter and removed or repositioned even after complete deployment, which makes the p64 stand out among other FDS [26].

Although large-scale randomized controlled trials are lacking, a recent single-center retrospective study of the p64 FDS was recently conducted [27]. Successful deployment was achieved in $97 \%$ of aneurysms and the rates of transient and permanent morbidity, and mortality were $5 \%, 1.7 \%$, and $0.8 \%$, respectively (Table 1) [27]. Three- and 9-month angiographic follow-ups showed complete occlusion in $58.5 \%$ and $87.7 \%$ of aneurysms, respectively. 


\section{Ongoing Trials}

FDS were initially applied to aneurysms that had failed prior therapy or to aneurysms unameanable to other treatment options. Currently, 2 major multicenter randomized clinical trials are planned to compare endovascular coiling with FDS. One is the Multicenter Randomized Trial on Selective Endovascular Aneurysm Occlusion with Coils versus Parent Vessel Reconstruction using the SILK Flow Diverter (MARCO POLO), and the other is the endovascular treatment of intracranial aneurysm with PED versus coils with or without stents (EVIDENCE) trial [37, 38]. Another trial, Flow Diversion in Intracranial Aneurysm Treatment (FIAT), comparing outcomes between flow diversion and best standard treatment (conservative, coiling or stenting), is also in the recruitment phase [33].

FDS have the potential to address high recanalization rates seen with some types of aneurysms after coil embolization. Presently in progress is the Complete Occlusion of Coilable Aneurysms (COCOA) study, a randomized, multicenter study comparing coiling with PED for treating small paraclinoid aneurysms (aneurysm diameter $<10 \mathrm{~mm}$ and neck diameter $<4 \mathrm{~mm}$ ). The safety end points are death and ipsilateral stroke, and the effectiveness end point is assessed with 6-month complete aneurysmal occlusion [39]. Finally, flow diverters have been allowed in the endovascular arm of the International Subarachnoid Aneurysm Trial II (ISAT II) [40]. This study and observational studies might provide some evidence for flow diverter use in the setting of ruptured aneurysms.

\section{Periprocedural and Postprocedural Management}

\section{Antiplatelet Therapy}

To minimize thromboembolic complications, dual antiplatelet therapy must be initiated prior to implantation of FDS. Although these regimens have not been standardized or compared head-to-head in randomized controlled trials, most studies pretreated patients for 5-7 days with aspirin 81-325 mg and clopidogrel $75 \mathrm{mg}$ daily, or, in some cases, a loading dose of aspirin 325-600 mg and clopidogrel 300-600 mg is administered hours prior to the procedure $[6,7,16,18,41,42]$. Dual antiplatelet therapy is typically continued for 6 months after the procedure, at which time clopidogrel may be stopped depending on angiographic and clinical results, while aspirin is typically continued indefinitely [6, 7, 16, 18, 41, 42]. In published series, thromboembolic complications, including instent thrombosis, have occurred upon stopping clopidogrel even after 3 months of follow-up [43]. Patients with stenosis after device implantation seem to be at a high risk of in-stent thrombosis upon discontinuation of clopidogrel [43]. The use of platelet aggregation tests and thromboelastography to measure medication resistance is controversial [44-46].
The decision to use ticagrelor, ticlopidine, cilostazol, or other antiplatelet medications in patients resistant to clopidogrel undergoing flow diverter implantation is based on data that have primarily been extrapolated from the cardiology literature. The need for antiplatelet therapy also complicates the use of flow diverters for the treatment of ruptured aneurysms in the acute period [47-50].

\section{Follow-up Imaging}

Aneurysm occlusion may take up to 6-12 months after a FDS is placed as endothelialization occurs [7]. Several grading systems have been proposed to evaluate the success of the endovascular intervention, including the Raymond-Roy Occlusion classification system, the Modified RaymondRoy classification, and several others.

Digital subtraction angiography remains the gold-standard test to assess residual aneurysm filling, owing to its high temporal and spatial resolution, but it is associated with a low, albeit existing risk, given the invasive character [51]. Magnetic resonance imaging (MRI) can be used to assess aneurysm thrombosis, cerebral edema, and mass effect after flow-diverter therapy [52]. In some cases following flow diversion, hyperintense signals on fluid-attenuated inversion recovery with circumferential contrast enhancement may be seen, and these may indicate aneurysmal inflammation as a local response to flow-diverter therapy [52].

Computed tomography angiography (CTA) is associated with lower spatial resolution and beam hardening artifact caused by metallic implants, which leads to degradation of image quality and limited utility. Flat panel detector CTA with intravenous contrast injection allows imaging of cerebrovascular anatomy with decreased contrast quantity and osmolarity, and less radiation exposure time; however, the resolution of the image remains a limiting factor. Further observational studies are necessary to clarify the role and utility of MRI and flat panel detector CTA in the follow-up of aneurysms treated with FDS.

\section{Procedural and Delayed Complications}

\section{Thromboembolic Events and Device Occlusion}

Acute and delayed thromboembolic events have been reported after flow diversion. Tan et al. [53] reported thromboembolic complications in $6.8 \%$ of patients treated with the PED for onand off-label indications. In-stent thrombosis is one of the gravest complications of flow diversion and may be encountered despite treatment with dual antiplatelet therapy or when clopidogrel is discontinued at 6 months [11, 12, 43, 54]. Patients with luminal narrowing following deployment of the FDS are at higher risk [43]. Further observational studies are necessary to clarify the incidence and risk factors for in-stent 
thrombosis, as are measures to reduce the risk of antiplatelet failure. Both clinically symptomatic and asymptomatic infarctions have been observed in vascular territories distant to the site of FDS deployment, and are believed to occur secondary to excessive manipulation during FDS deployment [11, 55].

\section{Intraprocedural Vessel Perforation/Rupture}

Intraprocedural vessel perforation/rupture during flow diversion may be avoided by appropriate size selection of the flow diverter, optimal vessel wall apposition, appropriate selection of proximal and distal landing zones, and cautious interventional manipulation $[12,43,56]$. Placing multiple overlapping FDS across eloquent branches and perforators leads to a reduction in the porosity and hence should be avoided if possible [14-16, 43, 57, 58]. High-quality evidence to guide this practice is lacking, and hence the risk needs to be weighed against conservative management and other treatment options.

\section{Perianeurysmal Edema}

The potential for developing perianeurysmal edema is a complication of flow diversion that the treating physician must be cognizant of. As the aneurysm thromboses, perianeurysmal inflammation and edema develop, which may precipitate a delayed clinical aggravation of symptoms consisting of headache with exacerbation of pre-existing compressive symptoms or the appearance of new compressive symptoms. This is best evaluated using MRI, which has shown vasogenic edema and blood-brain barrier breakdown between 3 and 15 days posttreatment [52]. Perianeurysmal edema has been described with large aneurysms and in aneurysms that are in close proximity to the brain without intervening cerebrospinal fluid space [52]. The optimal preventative and therapeutic measures for this complication have not been determined. Steroids have not been systematically studied in this setting and their response has been variable [52].

\section{Delayed Aneurysmal Rupture}

Delayed hemorrhage in the form of SAH develops in $4 \%$ of cases [59]. Delayed SAH may occur owing to enzymatic degradation of the aneurysm wall during thrombosis [43, 60, 61]. Hemodynamic alteration to flow and altered arterial compliance of the parent vessel by flow diversion is also hypothesized to cause delayed hemorrhage [62]. Another rare complication after flow diversion for the treatment of carotid cavernous aneurysms is the delayed rupture of a cavernous carotid aneurysm leading to the development of a carotid-cavernous fistula. This was noted in PUFS and has been noted with stent assisted coiling in the past [63].

\section{Delayed Parenchymal Hemorrhage}

Delayed hemorrhage in the form of intraparenchymal hemorrhage develops in $3 \%$ of cases [59]. The causes of such delayed distant hemorrhages remain unclear and are still issues of debate. Perforation with the distal wire of the delivery system of the FDS may explain some hemorrhagic complications (within $48 \mathrm{~h}$ of the procedure) but is unlikely to explain subacute or delayed bleeding. Cerebral infarct with secondary hemorrhagic conversion due to dual antiplatelet therapy has also been suspected as a potential etiology [62, 64].

To date, there is no consensus on the management of such delayed hemorrhages. Risks should be weighed between discontinuing antiplatelet therapy to prevent hematoma expansion, and the potential to develop in-stent thrombosis [62].

\section{“Off-Label” Usage of FDS}

As with other new medical technologies, experience with offlabel uses continues to develop. Wang et al. [65] conducted a meta-analysis of flow diversion in posterior circulation aneurysms. In their analysis of 220 patients, the rate of complete aneurysm occlusion at 6-month angiography was $84 \%$. The rate of procedure-related mortality was $15 \%$. Significantly higher mortality rates were noted among patients with giant aneurysms and basilar artery aneurysms. Ischemic stroke rate was $11 \%$ and perforator infarction rate was $7 \%$. Intraparenchymal hemorrhage rate was $4 \%$. Flow diversion for posterior circulation aneurysms is not FDA approved and thus should be conducted in carefully selected patients [65].

A recent meta-analysis of endovascular treatment of ruptured blister-like aneurysms included 240 reconstructive procedures, of which $62(25.8 \%)$ involved FDS. Mid- to longterm occlusion was $90.8 \%$. Perioperative morbidity and mortality were $12.6 \%$ and $8.7 \%$, respectively. Procedural complication rate was $17.0 \%$ with an early rebleeding rate of $6.5 \%$ [66]. Future research will likely focus on other less common off-label applications such as bifurcation aneurysms, dissecting aneurysms, and even acutely ruptured aneurysms.

\section{Conclusions}

FDS are rapidly shifting the landscape of endovascular options for the treatment of intracranial aneurysms and ushering in a new standard of care. Aneurysms that were previously deemed unamenable to endovascular therapy can now be safely treated. With continued innovation and enhancement of FDS, improved operator techniques, and antiplatelet regimens, there will hopefully be a reduction in procedure-related and delayed complications, thus widening the therapeutic spectrum for varied aneurysm morphology [67]. Awareness of these dramatic 
changes in the field of interventional neurology will allow the treating physicians to better advocate for their patients and to partake in the decision making process.

Required Author Forms Disclosure forms provided by the authors are available with the online version of this article.

Disclosures Fawaz Al-Mufti MD: Reports no disclosures

Krishna Amuluru MD: Reports no disclosures

Chirag Gandhi MD: Reports no disclosures

Charles Prestigiacomo MD: Reports no disclosures

\section{References}

1. Broderick JP, Brott TG, Duldner JE, Tomsick T, Leach A. Initial and recurrent bleeding are the major causes of death following subarachnoid hemorrhage. Stroke. 1994;25:1342-1347.

2. Molyneux AJ, Birks J, Clarke A, Sneade M, Kerr RS. The durability of endovascular coiling versus neurosurgical clipping of ruptured cerebral aneurysms: 18 year follow-up of the UK cohort of the International Subarachnoid Aneurysm Trial (ISAT). Lancet 2015;385:691-697.

3. Molyneux AJ, Kerr RS, Yu LM, et al. International subarachnoid aneurysm trial (ISAT) of neurosurgical clipping versus endovascular coiling in 2143 patients with ruptured intracranial aneurysms: a randomised comparison of effects on survival, dependency, seizures, rebleeding, subgroups, and aneurysm occlusion. Lancet 2005;366:809-817.

4. Zanaty M, Chalouhi N, Tjoumakaris SI, Rosenwasser RH, Gonzalez LF, Jabbour P. Flow-diversion panacea or poison? Front Neurol 2014;5:21.

5. Shapiro M, Becske T, Sahlein D, Babb J, Nelson PK. Stentsupported aneurysm coiling: a literature survey of treatment and follow-up. AJNR Am J Neuroradiol 2012;33:159-163.

6. Szikora I, Berentei Z, Kulcsar Z, et al. Treatment of intracranial aneurysms by functional reconstruction of the parent artery: the Budapest experience with the pipeline embolization device. AJNR Am J Neuroradiol 2010;31:1139-1147.

7. Lylyk P, Miranda C, Ceratto R, et al. Curative endovascular reconstruction of cerebral aneurysms with the pipeline embolization device: the Buenos Aires experience. Neurosurgery 2009;64:632-642.

8. Krishna C, Sonig A, Natarajan SK, Siddiqui AH. The expanding realm of endovascular neurosurgery: flow diversion for cerebral aneurysm management. Methodist Debakey Cardiovasc J 2014;10:214-219.

9. Canton G, Levy DI, Lasheras JC, Nelson PK. Flow changes caused by the sequential placement of stents across the neck of sidewall cerebral aneurysms. J Neurosurg 2005;103:891-902.

10. Lopes D, Sani S. Histological postmortem study of an internal carotid artery aneurysm treated with the Neuroform stent. Neurosurgery 2005;56:E416.

11. Becske T, Kallmes DF, Saatci I, et al. Pipeline for uncoilable or failed aneurysms: results from a multicenter clinical trial. Radiology 2013;267:858-868.

12. Nelson PK, Lylyk P, Szikora I, Wetzel SG, Wanke I, Fiorella D. The pipeline embolization device for the intracranial treatment of aneurysms trial. AJNR Am J Neuroradiol 2011;32:34-40.

13. Kadirvel R, Ding YH, Dai D, Rezek I, Lewis DA, Kallmes DF. Cellular mechanisms of aneurysm occlusion after treatment with a flow diverter. Radiology 2014;270:394-399.
14. Kallmes DF, Ding YH, Dai D, Kadirvel R, Lewis DA, Cloft HJ. A new endoluminal, flow-disrupting device for treatment of saccular aneurysms. Stroke 2007;38:2346-2352.

15. Yavuz K, Geyik S, Saatci I, Cekirge HS. Endovascular treatment of middle cerebral artery aneurysms with flow modification with the use of the pipeline embolization device. AJNR Am J Neuroradiol 2014;35:529-535.

16. Puffer RC, Kallmes DF, Cloft HJ, Lanzino G. Patency of the ophthalmic artery after flow diversion treatment of paraclinoid aneurysms. J Neurosurg 2012;116:892-896.

17. Liou TM, Li YC. Effects of stent porosity on hemodynamics in a sidewall aneurysm model. J Biomech 2008;41:1174-1183.

18. Augsburger L, Farhat M, Reymond P, et al. Effect of flow diverter porosity on intraaneurysmal blood flow. Klin Neuroradiol 2009;19: 204-214.

19. Lieber BB, Stancampiano AP, Wakhloo AK. Alteration of hemodynamics in aneurysm models by stenting: influence of stent porosity. Ann Biomed Eng 1997;25:460-469.

20. Sadasivan C, Cesar L, Seong J, et al. An original flow diversion device for the treatment of intracranial aneurysms: evaluation in the rabbit elastase-induced model. Stroke 2009;40:952-958.

21. Maimon S, Gonen L, Nossek E, Strauss I, Levite R, Ram Z. Treatment of intra-cranial aneurysms with the SILK flow diverter: 2 years' experience with 28 patients at a single center. Acta Neurochir (Wien) 2012;154:979-987.

22. Shankar JJ, Tampieri D, Iancu D, et al. SILK flow diverter for complex intracranial aneurysms: a Canadian registry. J Neurointerv Surg 2016;8:273-278.

23. Colby GP, Lin LM, Caplan JM, et al. Flow diversion of large internal carotid artery aneurysms with the surpass device: impressions and technical nuance from the initial North American experience. J Neurointerv Surg 2016;8:279-286.

24. Wakhloo AK, Lylyk P, de Vries J, et al. Surpass flow diverter in the treatment of intracranial aneurysms: a prospective multicenter study. AJNR Am J Neuroradiol 2015;36:98-107.

25. Mohlenbruch MA, Herweh C, Jestaedt L, et al. The FRED flowdiverter stent for intracranial aneurysms: clinical study to assess safety and efficacy. AJNR Am J Neuroradiol 2015;36:1155-1161.

26. Briganti F, Leone G, Marseglia M, Cicala D, Caranci F, Maiuri F. p64 Flow Modulation Device in the treatment of intracranial aneurysms: initial experience and technical aspects. J Neurointerv Surg 2016;8:173-180.

27. Fischer S, Aguilar-Perez M, Henkes E, et al. Initial experience with p64: a novel mechanically detachable flow diverter for the treatment of intracranial saccular sidewall aneurysms. AJNR Am J Neuroradiol 2015;36:2082-2089.

28. Kallmes DF, Hanel R, Lopes D, et al. International retrospective study of the pipeline embolization device: a multicenter aneurysm treatment study. AJNR Am J Neuroradiol 2015;36:108-115.

29. Murthy SB, Shah S, Venkatasubba Rao CP, Bershad EM, Suarez JI. Treatment of unruptured intracranial aneurysms with the pipeline embolization device. J Clin Neurosci 2014;21:6-11.

30. Colby GP, Lin LM, Caplan JM, et al. Immediate procedural outcomes in 44 consecutive Pipeline Flex cases: the first North American single-center series. J Neurointerv Surg 2015 Jul 1 [Epub ahead of print]

31. Gross BA, Frerichs KU. Stent usage in the treatment of intracranial aneurysms: past, present and future. J Neurol Neurosurg Psychiatry 2013;84:244-253.

32. Lubicz B, Van der Elst O, Collignon L, Mine B, Alghamdi F. Silk flow-diverter stent for the treatment of intracranial aneurysms: a series of 58 patients with emphasis on long-term results. AJNR Am J Neuroradiol 2015;36:542-546.

33. Murthy SB, Shah S, Shastri A, Venkatasubba Rao CP, Bershad EM, Suarez JI. The SILK flow diverter in the treatment of intracranial aneurysms. J Clin Neurosci 2014;21:203-206. 
34. Briganti F, Napoli M, Tortora F, et al. Italian multicenter experience with flow-diverter devices for intracranial unruptured aneurysm treatment with periprocedural complications - a retrospective data analysis. Neuroradiology 2012;54:1145-1152.

35. Stryker Neurovascular. Safety and Effectiveness of an Intracranial Aneurysm Embolization System for Treating Large or Giant Wide Neck Aneurysms (SCENT). Available at: https://clinicaltrials.gov/ ct2/show/NCT01716117. Accessed February 12016.

36. Microvention-Terumo, Inc. Pivotal Study of the MicroVention Flow Re-Direction Endoluminal Device (FRED) Stent System in the Treatment of Intracranial Aneurysms. Available at: https:// clinicaltrials.gov/ct2/show/NCT01801007?term=fred+ pivotal\&rank=1. Accessed February 12016.

37. Balt International. Efficacy trial of intracranial aneurysm treatment using two different endovascular techniques (Marco Polo). Availableat: http://www.clinicaltrials.gov/ct2/show/ NCT01084681?term $=$ Marco + Polo\&rank=1. Accessed February 12016.

38. Wong GK, Kwan MC, Ng RY, Yu SC, Poon WS. Flow diverters for treatment of intracranial aneurysms: current status and ongoing clinical trials. J Clin Neurosci 2011;18:737-740.

39. Chestnut Medical Technologies. California: Chestnut Medical Technologies. IDE annual report. Complet Occlusion of Coilable Aneurysms (COCOA) study; 2010. Available at: http://www.fda. gov/downloads/AdvisoryCommittees/.../ UCM247158.pdf. Accessed February 12016.

40. Centre Hospitalier de l'Universite' de Montre' al (CHUM). International Subarachnoid Aneurysm Trial II (ISAT II). Available at: http://clinicaltrials.gov/ct2/show/record/ NCT01668563. Accessed February 1st 2016.

41. Phillips TJ, Wenderoth JD, Phatouros CC, et al. Safety of the pipeline embolization device in treatment of posterior circulation aneurysms. AJNR Am J Neuroradiol 2012;33:1225-1231.

42. Berge J, Biondi A, Machi P, et al. Flow-diverter silk stent for the treatment of intracranial aneurysms: 1-year follow-up in a multicenter study. AJNR Am J Neuroradiol 2012;33:1150-1155.

43. De Vries J, Boogaarts J, Van Norden A, Wakhloo AK. New generation of Flow Diverter (surpass) for unruptured intracranial aneurysms: a prospective single-center study in 37 patients. Stroke 2013;44:1567-1577.

44. Sambu N, Radhakrishnan A, Dent H, et al. Personalised antiplatelet therapy in stent thrombosis: observations from the Clopidogrel Resistance in Stent Thrombosis (CREST) registry. Heart 2012;98: 706-711.

45. Comin J, Kallmes DF. Platelet-function testing in patients undergoing neurovascular procedures: caught between a rock and a hard place. AJNR Am J Neuroradiol 2013;34:730-734.

46. Gandhi CD, Bulsara KR, Fifi J, et al. Platelet function inhibitors and platelet function testing in neurointerventional procedures. $\mathrm{J}$ Neurointerv Surg 2014;6:567-577.

47. Suh JW, Lee SP, Park KW, et al. Multicenter randomized trial evaluating the efficacy of cilostazol on ischemic vascular complications after drug-eluting stent implantation for coronary heart disease: results of the CILON-T (influence of CILostazol-based triple antiplatelet therapy $\mathrm{ON}$ ischemic complication after drug-eluting stenT implantation) trial. J Am Coll Cardiol 2011;57:280-289.

48. Schleinitz MD, Olkin I, Heidenreich PA. Cilostazol, clopidogrel or ticlopidine to prevent sub-acute stent thrombosis: a meta-analysis of randomized trials. Am Heart J 2004;148:990-997.

49. Angiolillo DJ, Capranzano P, Goto S, et al. A randomized study assessing the impact of cilostazol on platelet function profiles in patients with diabetes mellitus and coronary artery disease on dual antiplatelet therapy: results of the OPTIMUS-2 study. Eur Heart J 2008;29:2202-2211.

50. Bertrand ME, Rupprecht HJ, Urban P, Gershlick AH. Double-blind study of the safety of clopidogrel with and without a loading dose in combination with aspirin compared with ticlopidine in combination with aspirin after coronary stenting : the clopidogrel aspirin stent international cooperative study (CLASSICS). Circulation 2000;102:624-629.

51. Kaufmann TJ, Huston J, 3rd, Mandrekar JN, Schleck CD, Thielen KR, Kallmes DF. Complications of diagnostic cerebral angiography: evaluation of 19,826 consecutive patients. Radiology 2007;243:812-819.

52. Berge J, Tourdias T, Moreau JF, Barreau X, Dousset V. Perianeurysmal brain inflammation after flow-diversion treatment. AJNR Am J Neuroradiol 2011;32:1930-1934.

53. Tan LA, Keigher KM, Munich SA, Moftakhar R, Lopes DK. Thromboembolic complications with Pipeline Embolization Device placement: impact of procedure time, number of stents and pre-procedure P2Y12 reaction unit (PRU) value. J Neurointervent Surg 2015;7:217-221.

54. Byrne JV, Beltechi R, Yarnold JA, Birks J, Kamran M. Early experience in the treatment of intra-cranial aneurysms by endovascular flow diversion: a multicentre prospective study. PLOS ONE 2010;5:e12492.

55. Shankar JJ, Vandorpe R, Pickett G, Maloney W. SILK flow diverter for treatment of intracranial aneurysms: initial experience and cost analysis. J Neurointerv Surg 2013;5(Suppl. 3):iii11-5.

56. Navarro R, Yoon J, Dixon T, Miller DA, Hanel RA, Tawk RG. Retrograde trans-anterior communicating artery rescue of unopened Pipeline Embolization Device with balloon dilation: complication management. J Neurointerv Surg 2015;7:e7.

57. Marinkovic S, Milisavljevic M, Kovacevic M. Interpeduncular perforating branches of the posterior cerebral artery. Microsurgical anatomy of their extracerebral and intracerebral segments. Surg Neurol 1986;26:349-359.

58. Marinkovic SV, Gibo H. The surgical anatomy of the perforating branches of the basilar artery. Neurosurgery 1993;33:80-87.

59. Brinjikji W, Murad MH, Lanzino G, Cloft HJ, Kallmes DF. Endovascular treatment of intracranial aneurysms with flow diverters: a meta-analysis. Stroke 2013;44:442-447.

60. Kulcsar Z, Houdart E, Bonafe A, et al. Intra-aneurysmal thrombosis as a possible cause of delayed aneurysm rupture after flowdiversion treatment. AJNR Am J Neuroradiol 2011;32:20-25.

61. Turowski B, Macht S, Kulcsar Z, Hanggi D, Stummer W. Early fatal hemorrhage after endovascular cerebral aneurysm treatment with a flow diverter (SILK-Stent): do we need to rethink our concepts? Neuroradiology 2011;53:37-41.

62. Cruz JP, Chow M, O'Kelly C, et al. Delayed ipsilateral parenchymal hemorrhage following flow diversion for the treatment of anterior circulation aneurysms. AJNR Am J Neuroradiol 2012;33:603-608.

63. Chan HW, Haliasos N, Derakhshani S, Vindlacheruvu R, Chawda S. Delayed caroticocavernous fistula after stent-assisted coil embolization of intracavernous carotid aneurysm: should we manage conservatively? Acta Neurochir (Wien) 2011;153:1291-1295.

64. Colby GP, Lin LM, Coon AL. Revisiting the risk of intraparenchymal hemorrhage following aneurysm treatment by flow diversion. AJNR Am J Neuroradiol 2012;33:E107.

65. Wang CB, Shi WW, Zhang GX, Lu HC, Ma J. Flow diverter treatment of posterior circulation aneurysms. A meta-analysis. Neuroradiology 2016;58:391-400.

66. Rouchaud A, Brinjikji W, Cloft HJ, Kallmes DF. Endovascular treatment of ruptured blister-like aneurysms: a systematic review and meta-analysis with focus on deconstructive versus reconstructive and flow-diverter treatments. AJNR Am J Neuroradiol 2015;36:2331-2339.

67. Fiorella D, Lylyk P, Szikora I, et al. Curative cerebrovascular reconstruction with the Pipeline embolization device: the emergence of definitive endovascular therapy for intracranial aneurysms. J Neurointerv Surg 2009;1:56-65. 